\title{
Online learning and design lectures during the COVID-19 pandemic:
} A student's experience

\author{
A.R. Adriyanto, I. Santosa \& A. Syarief \\ Bandung Institute of Technology, Indonesia
}

\begin{abstract}
The COVID-19 pandemic of 2020 caused changes in learning patterns throughout the world. Higher education was unprepared to provide online lectures to students and different learning platforms only were used sporadically for courses. Negative experiences therefore arose from this new learning process. This study uses a qualitative strategy approach to analyze a survey distributed to 193 students in April 2020. The survey aims to examine the experience of students in attending online lectures. Survey questions that are open-ended questions were analyzed by the affinity diagram technique. Four themes were found to be issues in the negative experiences of online learning, namely the reliability of information technology infrastructure, management of online learning, social presence, and student motivation. The results of these findings are expected to provide input for universities to manage future online learning in higher education.
\end{abstract}

Keywords: online learning, higher education, learning platforms, negative experiences

\section{INTRODUCTION}

In the face-to-face method in the physical classroom, the teacher is the center that controls the content and the learning process. Face-to-face learning is limited by space and time and the cost of learning is increasingly expensive. In online learning, students become the center of learning and demand independence, and the flexibility of location and time and unlimited access to knowledge are its strengths (Zhang et al. 2004).

The COVID-19 pandemic of 2020 caused changes in learning patterns throughout the world. Countries enforced rules that demanded that citizens stay at home, therefore teaching and learning activities that were previously carried out face-to-face in classrooms were replaced by using internet media to deliver lessons. Various types of platforms were used so that lectures could run, and these lectures were synchronously and asynchronously. However, in the process of all of this, various negative experiences emerged. A survey conducted by Adnan and Anwar (2020) in Pakistan found that most of the problems were related to limited access to the internet due to technical and financial problems. Students still prefer face-to-face meetings. The same situation occurred in West Bengal, India during the regional lockdown that occurred in the region. Students experienced problems such as depression, anxiety, poor internet connection, and uncomfortable learning environments at home (Kapasia et al. 2020). The qualitative study was carried out by Khalil et al. (2020) who analyzed synchronized online learning from the perspective of medical students. The thematic content analysis found four core themes, namely the educational impact, time management, challenges encountered, and preferences for the future. The challenges and opportunities for higher education in this pandemic were presented by Toquero (2020). This study recommends rearranging curriculum competencies and improving training for lecturers for online learning. This article aims to analyze the experience of higher education students attending online lectures during the COVID-19 pandemic in Indonesia. 


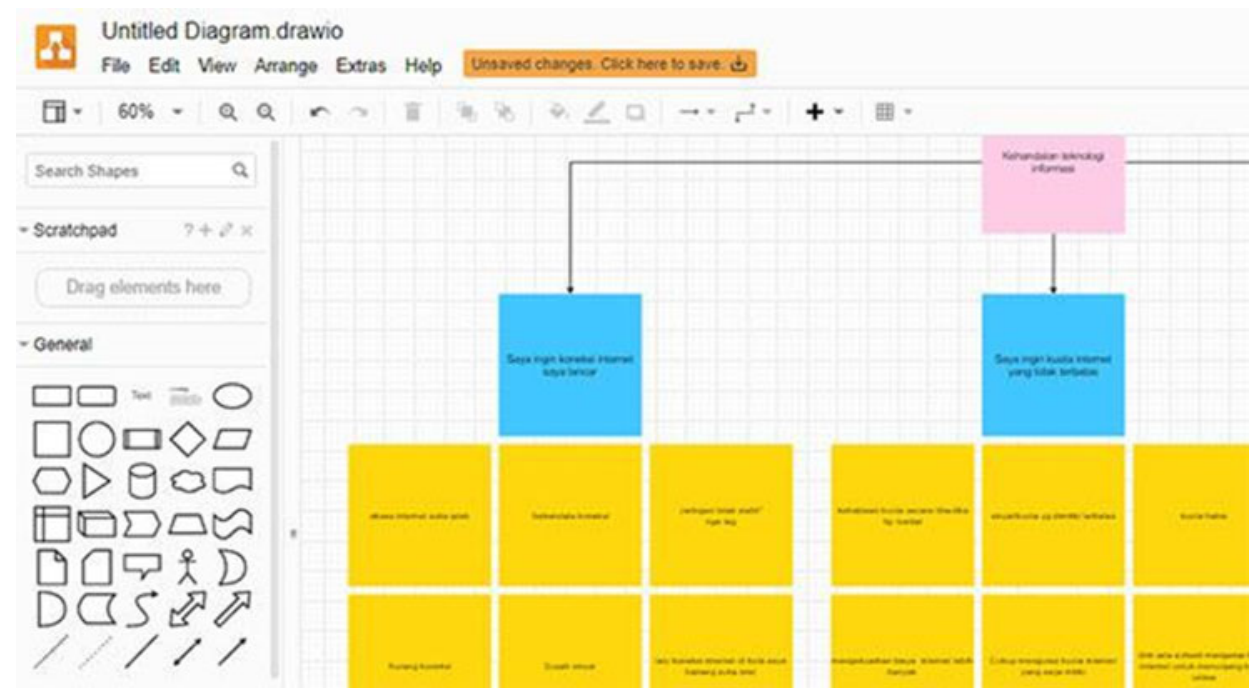

Figure 1. Diagram processing software (app.diagram.net).

\section{METHODS}

This study uses a qualitative strategy approach with data collections through online surveys. The online survey was conducted from April 7-17 2020 to obtain information related to student experiences with online learning. It used Google Forms by distributing the link via WhatsApp to students living in Indonesian cities such as Bandung, Jakarta, Yogyakarta, Surakarta, Pekanbaru, Makassar, and Semarang. In total, 193 students responded.

The survey consisted of 16 questions, some of which were closed, some of which were openended. This article focuses on respondents' answers to questions related to negative experiences in online learning during the pandemic. Online learning is focused on design courses which consist of practical and studio courses.

Open-ended questions produce a variety of answers from respondents. To analyze the diversity of answers, the affinity diagram technique was used recognize certain patterns in the answers. To process these answers, a diagram processing software (app.diagram.net) was used by entering each respondent's answer in a box (Figure 1). Boxes containing answers that are similar were grouped into one specific part. And in the end, the main themes of each group that are studied in this article were analyzed.

\section{RESULTS AND DISCUSSION}

The learning platform most widely used during this pandemic is Google Classroom, a learning management system from Google. Furthermore, the use of instant messaging such as on WhatsApp or LINE dominates the methods of learning through online media. Another popular platform was Zoom, a video-conferencing application that can sync face-to-face remotely. The Learning Management System (LMS) of educational institutions did not seem to be optimized to online learning during the time of the pandemic because of its non-dominant position. It is suspected that the issue of institutional readiness in preparing teaching material makes the choice of institutional LMS not the dominant usage (Figure 2). 


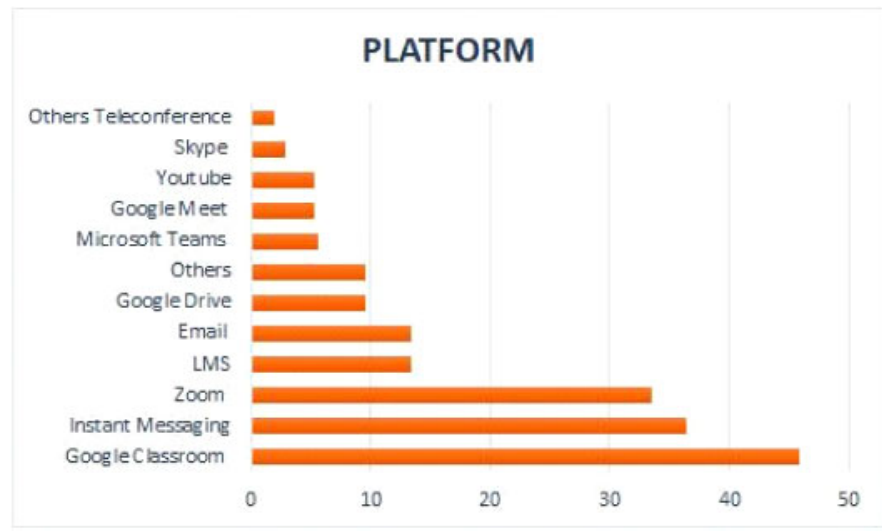

Figure 2. Learning platforms.

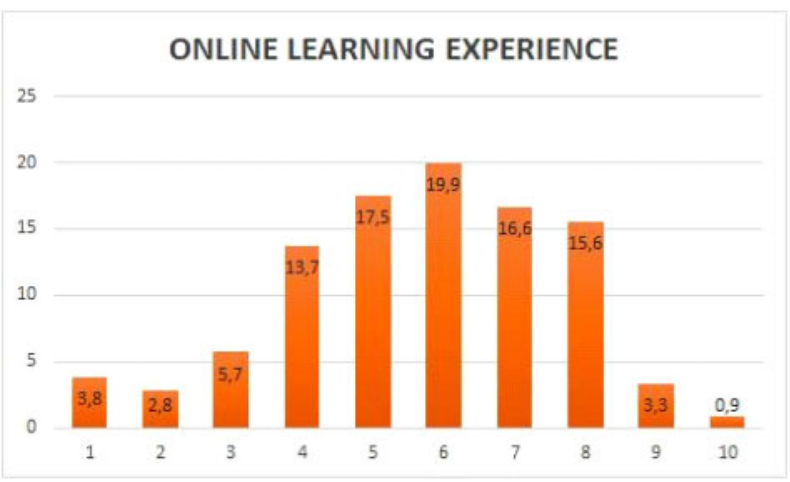

Figure 3. Online learning experience.

Google Classroom is asynchronous online learning when teachers and students are in different places at different times. It requires independence from students to understand the system and workflow in learning. In contrast, the Zoom application is an application that can be used for direct or synchronous learning. Teachers and students are present at the same time but in different locations. Assuming a stable internet connection, interactivity between teachers and students can run well. Instant messaging applications were widely used because of their popularity in everyday communication. The use of group features in communication allows one to communicate between people in groups that are created. Instant messaging is an application that has synchronous communication but can sometimes be delayed resulting in asynchronous communication.

On a scale of 1-10 respondents, were asked to rate the online learning they were taking. Score 6 became the most popular choice of respondents, followed by a score of 5 . Looking at this data, it is suspected that there were negative experiences experienced by respondents when attending online lectures. (Figure 3).

From the analysis of respondents' negative experiences in online lectures for practical and studio courses, four themes emerged:

a. the need for information technology infrastructure reliability,

b. the need for good online learning management,

c. the need for social presence and interaction, and

d. the need for student motivation in learning. 


\subsection{The need for information technology infrastructure reliability}

The problem that was primarily negative in online learning was that of information technology infrastructure when online lectures take place. This problem includes three groups of problems: internet network problems, internet quota limitations, and device problems used in the online lectures.

According to Bhuasiri et al. (2012), one dimension that influences the acceptance of online learning systems in developing countries is system dimension. System dimensions include infrastructure elements, and the quality of the internet infrastructure and the level of user information technology literacy is fundamental in the online learning process. To measure the level of information and communication technology development in an area, an index of information and communication technology development is used (BPS 2018). The index value is on a scale of 1-10, with the higher the index value indicating the more rapid development of information technology in a region.

Jakarta Province obtained the highest index value of 7.61, which contrasts with Papua province's index of 2.95. This shows that in a region that has a good internet network infrastructure, easier access to the internet network and the population allows for a greater ability of users to master computer technology. The lowest index besides Papua included the provinces of West Kalimantan, Lampung, Aceh, West Nusa Tenggara, North Maluku, West Sulawesi, and East Nusa Tenggara. Inequality in the development of information technology can be an obstacle to the implementation of online learning, especially if it is associated with the aim of increasing access to quality higher education.

\subsection{The need for good online learning management}

The next problem that contributes to the negative experience of respondents in online learning is the problem of managing online learning. This problem is covered in four groups of problems, namely lecture procedures, material understanding, assignments, and assistance processes.

Based on the negative experiences of students in managing online learning, several things can be concluded. Lecture procedures that are not clear and complicate the learning process are related to the application of rules in the online learning system used. Systems and procedures in online learning have not been optimally disseminated to teach participants. Sporadic use of various types of platforms is thought to create a large cognitive burden for teaching participants to understand each system one by one (Sweller et al. 2011).

Related to practical and studio courses contained in the design study program in general, an understanding of materials and tools is a major element in the design curriculum (Buchanan 1995). In distance learning in two different places, initial conditioning becomes a fundamental thing in practical and studio lectures. Both students and lecturers need to have the same material for the optimal learning process. The problems experienced in the survey were related to conditions that do not allow for material presence. The COVID-19 pandemic situation did not allow students and lecturers to get materials easily. In normal situations, learning materials might be presented more optimally for distance learning needs.

\subsection{The need for social presence and interaction}

The next problem that added to the negative experience of respondents in online learning was the absence of social presence and interaction. Although the distance between learners becomes virtually close, physical absence causes invisible nonverbal communication. Richardson and Swan (2003) discuss aspects of social presence in online learning in terms of satisfaction levels. The results of his research resulted in the discovery that there was a good level of satisfaction in students with the application of social presence aspects.

Rourke et al. (1999) focus on aspects of social presence by examining deeper aspects of the affective, interactive, and cohesive aspects of text-based material on computer media. The results of his research found that to create a social presence in computer-based media related affective, interactive, and cohesive aspects are needed. Affective aspects have indicators of emotional expression, 
use of humor, and self-disclosure. The interactive aspect has indicators of reconnecting the communication process, reference from other messages, explicit, reference, asking questions, expressing, and appreciating, and expressing signs of agreement. The cohesive aspect has vocative indicators aimed at a particular person, and refers to the group inclusively, making an open greeting. From these studies, it was concluded that social presence in online learning is realized through interaction with peers by including affective aspects in this digital realm.

\subsection{The need for student motivation in learning}

The negative experience of respondents in subsequent online learning is a matter of student motivation. Motivation can be divided into two parts, namely intrinsic motivation originating from within and extrinsic motivation that is triggered from outside the self. In the survey distributed to respondents, there are two groups that arise in motivational issues, namely self-motivation issues and learning environment problems.

On the environmental and personal dimensions in the online learning entities examined by Bhuasiri et al. (2012), there is intrinsic and extrinsic motivation. Intrinsic motivation is a voluntary drive from a person toward activity and aims to satisfy one's psychological needs. Motivation from within a person can be influenced by outside influences such as material use, clarity of instructions, regulations, social pressure, and competition.

According to Kawachi (2003), intrinsic motivation is stronger than extrinsic motivation and is directly related to the quality of deep learning. The formation of motivation is related to educational orientation. Educational orientation is divided into four parts, namely vocational, academic, social, and personal orientation. Vocational orientation is related to skill development while academic orientation is related to achieving intellectual interest. The formation of motivation related to vocational and academic orientation is obtained by bringing out the expressiveness in online teaching. The expression is defined as enthusiasm, friendliness, humor, dynamism, and charisma.

In online learning, students are physically separated from their peers and only meet virtually through the online class provided. The main factor in student failure in distance learning relates to students' feelings of being isolated without the support of their peers. In forming motivations related to this social orientation, online learning must facilitate the building of interaction between students in groups. Developing a sense of community can make learning effective.

\section{CONCLUSION}

Problems that arise in online learning vary. The government can increase investment in the development of information technology infrastructure so that various regions receive the same facilities as other regions. It is time for universities to focus on developing online learning management that takes into account social aspects and good interaction with learning content. For this reason, it is necessary to further analyze learning content that supports these aspects. Online learning user experience related to motivation deserves attention because of its independence in learning. Factors that can motivate students to learn in a fun way need to be further analyzed.

\section{REFERENCES}

Adnan, M. and Anwar, K. 2020. Online learning amid the COVID-19 pandemic: Students' perspectives. Journal of Pedagogical Sociology and Psychology, 2:45-51.

Bhuasiri, W., Xaymoungkhoun, O., Zo, H., Rho, J.J., and Ciganek, A.P. 2012. Critical success factors for e-learning in developing countries: A comparative analysis between ict experts and faculty, Computer \& Education, 58:843-855.

BPS, Biro Pusat Statistik. 2018. Tingkat pengangguran terbuka, data obtained from https://www.bps.go.id/ pressrelease/2018/11/05/1485/agustus-2018-tingkat-pengangguran-terbuka-tpt-sebesar-5-34-persen.html. 
Buchanan, M. 1995. Making art and critical literacy: a reciprocal relationship in Prentice, R., ed. Teaching art and design, addressing issues and identifying direction, London: Continuum.

Kapasiaa, N., Paulb, P., Royc, A., Sahac, J., Zaveric, A., Mallickc, R., Barmanc, B., Dasc, P., and Chouhanc, P. 2020. Impact of lockdown on learning status of undergraduate and postgraduate students during COVID-19 pandemic in West Bengal, India, Children and Youth Services Review, 116,:1-5.

Kawachi, P. 2003. Initiating intrinsic motivation in online education: Review of the current state of the art, Interactive Learning Environments, 11:59-81.

Khalil, R., Mansour, A.E., Fadda, W.A., Almisnid, K., Aldamegh, M., Al-Nafeesah, A., Alkhalifah, A., and AlWutayd, O. 2020. The sudden transition to synchronized online learning during the COVID-19 pandemic in Saudi Arabia: a qualitative study exploring medical students' perspectives, BMC Medical Education, 20:1-10.

Richardson, J.C. and Swan, K. 2003. Examining social presence in online courses in relation to students' perceived learning and satisfaction, Journal of Asynchronous Learning Networks, 7:68-88.

Rourke, L., Anderson, T., Garrison, D.R., and Archer, W. 1999. Assessing social presence in asynchronous text-based computer conferencing, International Journal of E Learning \& Distance Education, 14: 50-71.

Sweller, J., Ayres, P., and Kalyuga, S. 2011. Cognitive load theory, New York: Springer Science+Business Media.

Toquero, C.M., 2020. Challenges and Opportunities for Higher Education amid the COVID-19 Pandemic: The Philippine Context, Pedagogical Research, 5:1-5

Zhang, D., Zhao, J.L., Zhou, L., and Nunamaker, J.F. 2004. Can e-learning replace classroom learning?, Communication of $A C M, 47: 75-79$. 